\title{
Contraception in Iran: revolution and evolution
}

\section{Lindsay Edouard}

International Advisory Editor, Port Louis, Mauritius

\section{Correspondence to Professor Lindsay Edouard; soranae@gmail.com}

Received 16 November 2016 Revised 18 November 2016 Accepted 20 November 2016

\section{SLinked}

http://dx.doi.org/10.1136/ jfprhc-2015-101383

\section{CrossMark}

To cite: Edouard L. J Fam Plann Reprod Health Care 2017:43:5-6.
In this journal issue, Erfani provides new data addressing likely effects of the current pronatalist policy in Iran. Using data from the 2014 Tehran Survey of Fertility, this international study estimates the likely impact of policy change on future fertility and service delivery. It is a study that exemplifies the value of collaboration between countries which share values on good governance relating to the right to health. Drawing on funding and research resources in both Iran and Canada, which is home to a significant Iranian diaspora, this study anticipates major effects from the reduction of free contraceptive services on both demographic indicators at the population level and quality of care at the individual level. ${ }^{1}$ These changes can best be appreciated against the background of Iran's excellent track record in providing contraceptive services.

Family planning received international recognition in 1978 when it was included as a component of maternal and child health, and incorporated as an essential element of primary health care in the Alma Ata Declaration. Its acceptance has depended on both health and cultural advocacy, to different degrees in different regions. Whereas health benefits were often cited as the rationale for family planning service provision in sub-Saharan Africa, support from religious authorities, in the form of the more liberal interpretation of traditional texts, has been helpful in the Middle East. ${ }^{2}$

Iran's policy approach to contraception has been mixed. Ayatollah Khomeini supported contraceptive practice at the individual level whilst promoting a pronatalist policy at the community level. This approach is far from being conflictual given the distinct roles of interventions at the individual as opposed to community level: hence couples were given the opportunity to limit the size of their family size during the 1980s when a population increase was sought because the country was engaged in a major war.

Iran has undergone a fertility revolution during the last three decades. Socioeconomic development, especially for health, education and transport, had led to much improved living conditions by the mid-1980s. As a result, despite the prevailing pronatalist policy, the total fertility rate started to decrease around 1985 from more than 6 children per woman to 5.2 in 1989 when there was a major policy change with a reorientation of contraceptive care with intensified service delivery through health houses at the primary health care level. ${ }^{4}$ With the availability of effective contraceptive services, women were able to control their fertility, leading to a dramatic fall in the total fertility rate through the replacement level of around 2.1 in 2000 to 1.8 children per woman in 2011.

The national contraceptive prevalence rate for modern methods, including sterilisation, now hovers at around $60 \%$ with another $20 \%$ for traditional methods which are more popular among educated women. Fearing adverse side effects of modern methods, the latter group prefers to rely on emergency contraception in case of method failure. This Iranian family planning programme has been recognised by the World Health Organization as being a model. ${ }^{5}$

The dramatic turnaround in fertility has led to changes in policy. Worried by the demographic implications of the sweeping rise in contraception, policymakers in Iran have reconsidered the provision of contraceptive services that are free at service delivery points of the public health system. The analyses by Erfani of data from the 2014 Tehran Survey of Fertility demonstrate that the proposed restrictive services will likely selectively discriminate against disadvantaged groups, with their preference for long-acting contraceptive methods. 
According to the inverse care law, those most in need of health care are least likely to receive it: it is unfortunate that an intentional policy change would lead to this situation.

Government has no place in the bedrooms of the nation, either in relation to sexual orientation and practices or contraceptive methods. Individual choice is primary, and should reflect personal wishes. This approach should inform contraceptive care, by addressing the unmet needs of disadvantaged groups and overcoming access barriers to a range of methods. ${ }^{6}$ Otherwise, the health of women is likely to suffer, through an increase in unplanned pregnancy and induced abortion, with higher maternal morbidity and mortality. Whereas policy formulation is the prerogative of decision makers, health practitioners have the duty of advocacy by communicating the anticipated impact of proposed changes on the health of populations so that corrective actions can be implemented.

Competing interests The author carried out assignments in Iran in 1984 with the World Health Organization for a review of primary health care and in 1987 with the United Nations Fund for Population Activities for the reorientation of the national family planning programme.

Provenance and peer review Commissioned; internally peer reviewed.

\section{REFERENCES}

1 Erfani A. Curbing publicly-funded family planning services in Iran: who is affected? J Fam Plann Reprod Health Care 2017;43:37-43.

2 Omran AR. Family Planning in the Legacy of Islam. New York, NY: Routledge, 1992:168-177, 184-194.

3 Potts M, Mahmood A, Graves AA. The pill is mightier than the sword. Int J Health Policy Manag 2015;4:507-510.

4 Modrek S, Ghobadi N. The expansion of health houses and fertility outcomes in rural Iran. Stud Fam Plann 2011;42:137-146.

5 Eslami M, d'Arcangues C. Aiming for quality in Iran's national family planning program - two decades of sustained efforts. Contraception 2016;93:209-215.

6 Edouard L. The right to contraception and the wrongs of restrictive services. Int J Gynaecol Obstet 2009;106:156-159.

\section{FACULTY OF SEXUAL \& REPRODUCTIVE HEALTHCARE MEMBERSHIP EXAMINATION}

The Membership Examination (MFSRH) consists of:

- Part 1 Single Best Answer paper (SBA)

London-based examination held annually in April and October. Applications for April 2017 examination must be received by 9th January 2017. The syllabus for the Part 1 examination is on the FSRH website.

\section{- Evidence Based Commentary (EBC)}

Candidates can view the released topic and candidate guidance notes on the FSRH website. (Please note- you will now need to register on the new FSRH website before accessing this information.) There is an absolute deadline of $\mathbf{3 1}$ August $\mathbf{2 0 1 7}$ to submit the EBC on this topic. You can submit an EBC before applying to enter the Part 1 examination.

- Part 2 Examination (CRQ, EMQ, OSCE)

Applications for the MFSRH Part 2 to be held 8th June 2017 must be received by 9th January 2017.

Further information and the Part 2 Syllabus are on the FSRH website. The qualification is subject to re-certification every 5 years. For the current MFSRH Examination Regulations, information on all components of the MFSRH examination and application forms, please visit the Faculty of Sexual and Reproductive Healthcare Website: https://www.fsrh.org/careers-andtraining/membership-exams/ or contact examsofficer@fsrh.org 